\title{
Genetic evaluation of the growth of beef bulls at a performance test station
}

\author{
L. Vostrý1,2,3, Z. Veselá2 and E. Krupa ${ }^{2}$ \\ ${ }^{1}$ Czech University of Life Sciences Prague, Faculty of Agrobiology, Food and Natural Resources, \\ Department of Genetics and Breeding, 16521 Prague, Czech Republic \\ ${ }^{2}$ Institute of Animal Science, 10400 Prague - Uhrininěves, Czech Republic
}

KEYWORDS: beef cattle, growth, genetic parameters, breeding value, model adequacy

Received: 7 February 2013

Revised: 29 July 2013

Accepted: 29 November 2013

${ }^{3}$ Corresponding author: e-mail: vostry@af.czu.cz

\begin{abstract}
Genetic evaluation of the growth of bulls at a performance test station was performed using a single-trait model (STAM) and multi-trait models that included pre-weaning growth. The growth of the bulls was represented by the average daily gain in the test (ADGT). Pre-weaning growth was expressed as average daily gains from birth to 120 days of age (ADG120) and from 120 to 210 days of age (ADG210). The coefficient of heritability across breeds was estimated by all models to be approximately 0.17 for ADG120, 0.13 for ADG210, and 0.27 for ADGT. Some tested models included the random effect of direct permanent environment. All testing criteria prioritized the multi-trait model incorporating the direct permanent effect, which was the most important effect in the model. The values of Spearman's coefficients of correlation between breeding value predicted by the single-trait and multi-trait models were 0.93 , and in the particular models that evaluated $10 \%, 5 \%$ and $1 \%$ of the best sires, the values ranged from 0.76 to 0.83 .
\end{abstract}

\section{Introduction}

Growth is a very complex trait. In genetic or feeding experiments, the growth ability of cattle is generally represented by body weight at different ages or average daily gains in a defined time period (Bartoň et al., 2007). For genetic evaluation of the growth abilities of farm animals, single-trait (STAM) or multi-trait animal models are used most frequently. When longitudinal data are used, an animal model with random regression is employed (Meyer, 1998; Krejčova et al., 2008).

For accurate evaluation of the growth ability of bulls, it is necessary to determine the significant effects influencing the growth of the bulls under study. Growth is a cumulative trait in which weight gain at a given moment is influenced by the history of the animal. It was demonstrated in several studies that the herd-of-origin effect was closely related to the growth ability of bulls (Přibylová et al., 2004; Schenkel et al., 2004; Nephawe et al., 2006). This may be because of the possibility that environmental conditions and herd management cause variability in baseline weights that, in turn, influence average daily weight gains during the study. The influence of preweaning environmental conditions may persist until the end of the study, however. Přibyl et al. (2003) reported that dam age influenced the pre-weaning growth of calves and that it may also influence the post-weaning growth of bulls. The significance of the effect of dam age on the growth abilities of bulls was confirmed by Přibylová et al. (2004). Different 
herd conditions lead to growth compensation in animals, which should be distinguished from the effect of genetic constitution. Therefore, the direct permanent environment is usually taken into consideration in repeated performance records (longitudinal data) (Přibyl et al., 2008a,b). Přibyl et al. (2008a,b) stated that weight gain in consecutive growth segments was a more suitable marker of growth than body weight because it allows the effects of fixed and random environments, which influence animal growth during particular periods, to be more clearly determined.

Bulls are tested at central stations in many countries to compare different herds under standardized environmental conditions. Estimates of genetic parameters and predicted breeding values are currently obtained using the BLUP procedure (Henderson, 1975). Woodward et al. (1992) reported that the assumptions and properties of BLUP require that the unknown (co)variance components be substituted with the most accurate estimates available. The selection of animals can influence genetic parameters estimated from their performance records (Schaeffer et al., 1997). Bulls undergo intense growth at performance test stations compared with those reared in grazing systems. After weaning, particular bulls are chosen to be moved to rearing facilities. Only those bulls that come from selected dams and sires and satisfy the conditions of the breeding programme of a given breed are transferred to the rearing facilities. Standardized nutrition and management methods are used at the performance test stations. Schaeffer et al. (1997) reported that sequential selection has a major effect on genetic parameter estimates and necessitates the use of specific statistical tests. The use of a multi-trait animal model to evaluate bull testing that includes a field test may diminish the influence of pre-selection of bulls on the evaluation of average daily gain in the test (ADGT). The objectives of this paper are the estimation of genetic parameters, prediction of breeding values, and analysis of the influence of pre-weaning growth, as defined by average daily weight gains, on the subsequent weight gain of beef bulls.

\section{Material and methods}

Data on average daily gains from a field test and from performance test stations were provided by the Czech Beef Breeders Association (www.cschms. $\mathrm{cz}$ ). The evaluation was performed using the multibreed animal model (AM) with genetic groups incorporated into the relationship matrix according to Westell et al. (1988). Nine breeds of beef cattle were included in the analysis: Beef Simental (20\%), Belgian Blue (3\%), Gasconne (3\%), Hereford (7\%), Aberdeen Angus (23\%), Charolais (30\%), Limousine (8\%), Blonde d'Aquitane (3\%) and Piemontese (3\%). Each breed was represented by animals with an $88 \%-100 \%$ gene share of the given breed and born during 1990-2005. The input database was adjusted so that the components of variance among all of the considered effects in all traits could be estimated. Pre-weaning growths were defined by average daily gains. Only animals that were descendants of a sire with 5 or more offspring, sires that had offspring in at least two contemporary groups (Herd-Year-Season: HYS), dams with two or more offspring, and bulls born within contemporary groups (HYS) exceeding at least 5 animals were considered (Vostrý et al., 2007).

Table 1. Models

\begin{tabular}{|c|c|c|c|c|c|c|c|c|c|c|c|}
\hline Model & & AgeD & SEX & HYS & HLCO & $b A B+b^{2} A B$ & $b W W+b^{2} W W$ & a & $\mathrm{m}$ & peM & peA \\
\hline \multirow{2}{*}{1} & PWW & $F=$ fixed & $\mathrm{F}$ & $\mathrm{F}$ & & & & $\mathrm{R}=$ random & & $\mathrm{R}$ & \\
\hline & ADGT & $\mathrm{F}$ & & $\mathrm{F}$ & $F$ & $F$ & & $\mathrm{R}$ & & & \\
\hline \multirow{2}{*}{2} & PWW & $\mathrm{F}$ & $\mathrm{F}$ & $\mathrm{F}$ & & & & $\mathrm{R}$ & $\mathrm{R}$ & $\mathrm{R}$ & $\mathrm{R}$ \\
\hline & ADGT & $\mathrm{F}$ & & $\mathrm{F}$ & $\mathrm{F}$ & $F$ & & $\mathrm{R}$ & & & $\mathrm{R}$ \\
\hline \multirow{2}{*}{3} & PWW & $\mathrm{F}$ & $\mathrm{F}$ & $\mathrm{F}$ & & & & $\mathrm{R}$ & $\mathrm{R}$ & $\mathrm{R}$ & \\
\hline & ADGT & $\mathrm{F}$ & & $\mathrm{F}$ & $\mathrm{F}$ & $\mathrm{F}$ & $\mathrm{F}$ & $\mathrm{R}$ & & & \\
\hline \multirow{2}{*}{4} & PWW & $\mathrm{F}$ & $\mathrm{F}$ & $\mathrm{F}$ & & & & $\mathrm{R}$ & $\mathrm{R}$ & $\mathrm{R}$ & $\mathrm{R}$ \\
\hline & ADGT & $\mathrm{F}$ & & $\mathrm{F}$ & $\mathrm{F}$ & $\mathrm{F}$ & $\mathrm{F}$ & $\mathrm{R}$ & & & $\mathrm{R}$ \\
\hline \multirow{2}{*}{5} & PWW & $\mathrm{F}$ & $\mathrm{F}$ & $\mathrm{F}$ & & & & $\mathrm{R}$ & $\mathrm{R}$ & $\mathrm{R}$ & $\mathrm{R}$ \\
\hline & ADGT & $\mathrm{F}$ & & $\mathrm{F}$ & & $\mathrm{F}$ & & $\mathrm{R}$ & & & $\mathrm{R}$ \\
\hline STAM & ADGT & $\mathrm{F}$ & & $\mathrm{F}$ & $\mathrm{F}$ & $\mathrm{F}$ & & $\mathrm{R}$ & & & \\
\hline
\end{tabular}

STAM - single-trait animal model, PWW- pre-weaning weight (ADG120, ADG210), ADGT-average daily gain in performance test stations, AgeD - effect of dam's age, SEX - effect of sex, HYS - preweaning: effect of herd $\times$ year $\times$ season; test station: test station $\times$ year $\times$ season, HLCO

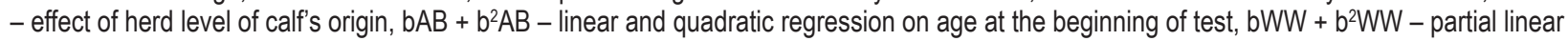
and quadratic regression on WW, a - direct additive genetic effect, $\mathrm{m}$ - maternal additive genetic effect, peM - maternal permanent environment effect, peA - direct permanent environmental effect 
Data. The data included 24,017 average daily gains from birth to 120 days of age (ADG120) and 16,427 average daily gains from 120 to 210 days of age (ADG210) for male and female calves. Data from the performance test station comprised 3,429 average daily gains of tested bulls (ADGT). All evaluated animals were offspring from 1,097 sires and 9,246 dams. A relationship matrix was composed of 47,098 animals.

Statistical model. Genetic parameters were evaluated by using a multi-trait model involving ADG120, ADG210 and ADGT. Different models (Table 1) were tested for the estimation of genetic parameters and prediction of breeding values (Přibyl et al., 2003; Přibylová et al., 2004). In this study, contrary to standard evaluation, HYS was included as a fixed effect in the model of pre-weaning growth evaluation. The tested models included the following fixed effects: effect of herd $\times$ year $\times$ season, age of dam, sex, breed of calf, effect of herd level of the calf's origin, linear and quadratic regression of age at the beginning of the test, linear and quadratic regression of weaning weight. The following random effects were included: direct and maternal genetic effects, maternal permanent environment effect, direct permanent environmental effect and residual error. The fixed effect of HYS included 1804 classes for ADG120, 1112 classes for ADG210 and 113 classes for ADGT. The age of dam parameter included five classes: $<2,2-3,3-4,4-5,>5$ years old. Sex included four classes: bull, bull twins, heifer and heifer twins. The herd level of a calf's origin included five classes. The structure of the tested models is shown in Table 1. Bulls were the offspring of highly selected dams and sires from the whole population. There was usually only one son tested per dam. The maternal effect was not included in the model for ADGT traits.

We assume that direct genetic effect $(a)$ and maternal genetic effect $(m)$ are significantly correlated and that the remaining effects [random direct permanent environmental effect (peA), maternal permanent environmental effect ( $p e M$ ), and residual error $(e)]$ are independent of each other within the particular traits. We also assume that the effects show normal random distribution with zero average and (co)variances given by the matrix $(\mathrm{V})$ :

$$
V\left[\begin{array}{c}
a \\
m \\
p e M \\
p e A \\
e
\end{array}\right]=\left[\begin{array}{ccccc}
A \otimes G_{0} & A \otimes C_{0} & 0 & 0 & 0 \\
A \otimes C_{0} & A \otimes M & 0 & 0 & 0 \\
0 & 0 & I \sigma_{p e M}^{2} & 0 & 0 \\
0 & 0 & 0 & I \sigma_{p e A}^{2} & 0 \\
0 & 0 & 0 & 0 & I \sigma_{e}^{2}
\end{array}\right]
$$

where: $G_{0}$ - the covariance matrix for additive genetic effects, $M_{0}$ - the covariance matrix for maternal genetic effects, $C_{0}$ - the covariance matrix between direct additive and maternal genetic effects, $\sigma_{p e A}^{2}$ - the variance of the effect of permanent direct environment, $\sigma_{e}^{2}-$ the variance of the effect of residual error, $A$ - the relationship matrix, and $I-$ the identity matrix.

The REMLF90 computation programme was used for the estimation of variance and covariance components (Misztal et al., 2002). The following population parameters were derived from the estimated variance-covariance components:

$\sigma_{y}^{2}$ - phenotype variance $\left[\sigma_{y}^{2}=\sigma_{a}^{2}+\sigma_{m}^{2}+\sigma_{a m}^{2}+\sigma_{p e M}^{2}\right.$ $\left.+\sigma_{p e A}^{2}+\sigma_{e}^{2}\right]$

$h_{a}^{2}-$ coefficients of direct heritability $\left[h_{a}^{2}=\sigma_{a}^{2} / \sigma_{y}^{2}\right]$

$h_{m}^{2}-$ coefficients of maternal heritability $\left[h_{m}^{2}=\frac{a}{=} \sigma_{m}^{2} / \sigma_{y}^{2}\right]$ $c^{2}-$ the ratio of the direct permanent environment variance to phenotype variance $\left[c^{2}=\sigma_{p e A}^{2} / \sigma_{y}^{2}\right]$

The suitability of multi-trait models was tested on the basis of estimated values of residual variance $\left(\sigma_{e}^{2}\right)$ and Akaike's information criterion (AIC; Bozdogan, 2000):

$$
\mathrm{AIC}=-2 \log L(\theta)+2 d
$$

where: $\log L(\theta)$ - the natural $\log$ arithm of likelihood function and $d$ - the number of free parameters in the model.

The suitability of models was also tested by the likelihood ratio test (LRT; Kaps and Lamberson, 2004), which is based on a comparison of the values of the likelihood function of two models.

$$
\chi^{2}=-2 \log \frac{L(\text { reduced })}{L(\text { full })}=2[-\log L(\text { reduced })+\log L(\text { full })
$$

where: $\chi^{2}$ - the value of the chi-square test, $L$ (reduced) - the value of the likelihood function of a reduced model (a model without the effect of direct permanent environment), $L$ (full) - the value of the likelihood function of a full model (a model with the direct permanent environment effect).

The estimates of variance components, which were computed using the multi-trait model, were compared with the estimates of variance components obtained for ADGT on the same data using the same model effects as those described elsewhere (Přibylová et al., 2004).

Breeding values were estimated by the BLUPF90 computation programme (Misztal et al., 2002). 


\section{Results}

Table 2 shows the estimated variances of the genetic and environmental parameters, the variance of the residual error, and AIC and LRT of the tested models for the average daily gains. The values of AIC could only be compared between models 1 vs 2 and 3 vs 4 because the fixed effects of other pairs of models were not the same. The values of AIC were lowest in those models that included the random effect of direct permanent environment ( $p e A$ ) (models 2 vs 1 and 4 vs 3 ). The lower values of AIC indicate statistical significance of the random effect of direct permanent environment in the model. The values of $\sigma_{e}^{2}$ revealed that the inclusion of fixed regression in WW did not markedly influence the estimation of $\sigma_{e}^{2}$. In contrast, the model that included the fixed effect of direct permanent environment showed a significant reduction in the value of $\sigma_{e}^{2}$ (models 2 vs 1 and 4 vs 3 ). The inclusion of fixed regression on weaning weight, in addition to the random effect of direct permanent environment, resulted in a reduction of $\sigma_{e}^{2}$ in ADG210 and ADGT. The omission of the fixed effect of HLCO (model 5) caused a further decrease in the value of residual variance in ADGT compared with model 2. The omission of the fixed effect of HLCO led to a negligible increase in residual variance in ADG210, however. The trait ADG120 was not influenced by the omission of fixed effect of HLCO. The lower values of $\sigma_{e}^{2}$, as well as the lower values of AIC, indicated the greater suitability of the multi-trait model with the random effect of direct permanent environment over the other models.

The estimates of genetic and environmental parameters for the tested models showed very similar values. The highest value of $\sigma_{a}^{2}$ was estimated in model 5 , and the lowest value was obtained in model 4 for all traits. The maternal genetic effect was highest for ADG120, but lowest for ADG210 in model 2. The highest value of $\sigma_{p e A}^{2}$ was estimated in model 5 and the lowest value in model 4 for ADG120. The inclusion of the fixed effect of HLCO reduced the variability of direct genetic effect and variability of the direct permanent environment. Residual variance $\left(\sigma_{e}^{2}\right)$ was highest in models 1 and 3 for all studied traits. The lowest value of $\sigma_{e}^{2}$ for ADG120 was estimated in model 2 but was found to be lowest for ADG210 and ADGT in model 4. The value of $\sigma_{e}^{2}$ for the single-trait animal model was lower than the values of $\sigma_{e}^{2}$ estimated by the tested models 1 and 3 , but higher than the values estimated by models 2,4 and 5, which included the random effect of direct permanent environment.

Table 3 shows the estimated values of the coefficient of direct and maternal heritability $\left(h_{a}^{2}, h_{m}^{2}\right)$, the genetic correlations of direct and maternal effect $\left(r_{a}\right.$, $\left.r_{m}\right)$, and the correlations between direct and maternal effect $\left(r_{a m}\right)$. Estimates of heritability for the direct genetic effect in all models were approximately 0.17 for ADG120, approximately 0.13 for ADG210

Table 2. Estimates of genetic and environmental parameters

\begin{tabular}{|c|c|c|c|c|c|c|c|c|}
\hline Model & Traits & AIC & $\sigma_{a}^{2}$ & $\sigma_{m}^{2}$ & $\sigma_{p e M}^{2}$ & $\sigma_{p e A}^{2}$ & $\sigma_{e}^{2}$ & $P$-values \\
\hline \multirow[t]{3}{*}{ Model 1} & ADG120 & & 5934 & 4396 & 5186 & & 22000 & \multirow{6}{*}{$<0.0001$} \\
\hline & ADG210 & 386234 & 6044 & 1716 & 1406 & & 37480 & \\
\hline & ADGT & & 12810 & & & & 34000 & \\
\hline \multirow[t]{3}{*}{ Model 2} & ADG120 & & 5932 & 4405 & 5179 & 11040 & 10960 & \\
\hline & ADG210 & 386070 & 5952 & 1639 & 1405 & 8300 & 29230 & \\
\hline & ADGT & & 12740 & & & 1249 & 32800 & \\
\hline \multirow[t]{3}{*}{ Model 3} & ADG120 & & 5926 & 4380 & 5208 & & 22000 & \multirow{6}{*}{$<0.0001$} \\
\hline & ADG210 & 386054 & 6066 & 1721 & 1409 & & 37470 & \\
\hline & ADGT & & 12610 & & & & 34000 & \\
\hline \multirow[t]{3}{*}{ Model 4} & ADG120 & & 5923 & 4382 & 5209 & 10180 & 11820 & \\
\hline & ADG210 & 385910 & 6028 & 1697 & 1407 & 9789 & 27700 & \\
\hline & ADGT & & 12570 & & & 1337 & 32690 & \\
\hline \multirow[t]{3}{*}{ Model 5} & ADG120 & & 5936 & 4381 & 5202 & 11310 & 10690 & \\
\hline & ADG210 & 386135 & 6093 & 1787 & 1398 & 8197 & 29250 & - \\
\hline & ADGT & & 13080 & & & 1277 & 32790 & \\
\hline STAM & ADGT & & 12830 & & & & 33850 & - \\
\hline
\end{tabular}

ADG120 - average daily gains from birth to 120 days, ADG210 - average daily gains from 120 to 210 days of age, ADGT - average daily gains of tested bulls, AIC - Akaike's information criterion, $\sigma_{a}^{2}-$ direct additive genetic variance, $\sigma_{m}^{2}-$ maternal additive genetic variance, $\sigma_{p e M}^{2}$ - permanent maternal environment variance, $\sigma_{p e A}^{2}$ - permanent direct environment variance, $\sigma_{e}^{2}-$ residual variance , $P$-values - likelihood ratio test; STAM - single-trait model 
Table 3. Estimates of coefficients of direct and maternal heritability (diagonal), direct and maternal correlations and correlations between direct and maternal effects (above diagonal)

\begin{tabular}{|c|c|c|c|c|c|c|}
\hline Model & Traits & ADG120-a & ADG210-a & ADGT-a & ADG120-m & ADG210- $m$ \\
\hline & ADG120-a & 0.172 & 0.480 & 0.252 & -0.595 & -0.092 \\
\hline & ADG210-a & & 0.132 & 0.111 & -0.242 & -0.231 \\
\hline \multirow[t]{5}{*}{ Model 1} & ADGT-a & & & 0.274 & 0.070 & 0.336 \\
\hline & ADG120-m & & & & 0.128 & 0.791 \\
\hline & ADG210-m & & & & & 0.037 \\
\hline & ADG120-a & 0.172 & 0.480 & 0.250 & -0.594 & -0.086 \\
\hline & ADG210-a & & 0.130 & 0.098 & -0.243 & -0.205 \\
\hline \multirow[t]{5}{*}{ Model 2} & ADGT-a & & & 0.272 & 0.070 & 0.369 \\
\hline & ADG120-m & & & & 0.128 & 0.798 \\
\hline & ADG210-m & & & & & 0.036 \\
\hline & ADG120-a & 0.171 & 0.479 & 0.243 & -0.596 & -0.094 \\
\hline & ADG210-a & & 0.132 & 0.089 & -0.241 & -0.238 \\
\hline \multirow[t]{5}{*}{ Model 3} & ADGT-a & & & 0.271 & 0.058 & 0.321 \\
\hline & ADG120-m & & & & 0.127 & 0.791 \\
\hline & ADG210-m & & & & & 0.037 \\
\hline & ADG120-a & 0.180 & 0.478 & 0.240 & -0.597 & -0.090 \\
\hline & ADG210-a & & 0.131 & 0.079 & -0.245 & -0.228 \\
\hline \multirow[t]{5}{*}{ Model 4} & ADGT-a & & & 0.270 & 0.058 & 0.341 \\
\hline & ADG120-m & & & & 0.133 & 0.798 \\
\hline & ADG210-m & & & & & 0.037 \\
\hline & ADG120-a & 0.158 & 0.477 & 0.239 & -0.597 & -0.089 \\
\hline & ADG210-a & & 0.130 & 0.082 & -0.250 & -0.248 \\
\hline \multirow[t]{3}{*}{ Model 5} & ADGT-a & & & 0.277 & 0.078 & 0.362 \\
\hline & ADG120-m & & & & 0.117 & 0.797 \\
\hline & ADG210-m & & & & & 0.038 \\
\hline STAM & $A D G T$ & & & 0.275 & & \\
\hline
\end{tabular}

ADG120 - average daily gains from birth to 120 days, ADG210 - average daily gains from 120 to 210 days of age, ADGT - average daily gains of tested bulls, a - direct additive genetic effect, $m$-maternal genetics effect, STAM - single-trait model

Table 4. Estimates of the ratio of the direct permanent environment variance to phenotype variance (diagonals) and correlations between direct permanent environmental effects (above diagonals)

\begin{tabular}{|c|c|c|c|c|c|c|c|c|c|}
\hline \multirow[t]{2}{*}{ Traits } & \multicolumn{3}{|c|}{ Model 2} & \multicolumn{3}{|c|}{ Model 4} & \multicolumn{3}{|c|}{ Model 5} \\
\hline & ADG120 & ADG210 & ADGT & ADG120 & ADG210 & ADGT & ADG120 & ADG210 & ADGT \\
\hline ADG120 & 0.320 & 0.212 & 0.381 & 0.309 & 0.204 & 0.222 & 0.301 & 0.211 & 0.419 \\
\hline ADG210 & & 0.181 & -0.388 & & 0.213 & -0.549 & & 0.175 & -0.366 \\
\hline ADGT & & & 0.027 & & & 0.029 & & & 0.027 \\
\hline
\end{tabular}

and approximately 0.27 for ADG. The estimates for maternal genetic effects in all models were approximately 0.12 for ADG120 and approximately 0.04 for ADG210. The $h_{a}^{2}$ estimated by the single-trait animal model reached similar values as in the tested models. The value of $h_{m}^{2}$ for ADG120 accounts for $75 \%$ of the $h_{a}^{2}$ value in all the tested models. Genetic correlations among direct effects across traits were low to moderate and positive. The highest value of genetic correlation between direct effects $\left(r_{a}\right)$ was estimated between ADG120 and ADG210. A moderate correlation between direct effects was determined between ADGT and the other average daily gains.

The genetic correlation between direct and maternal effect was negative. Positive values were cal- culated for $r_{a m}$ between maternal effect for ADG120 and ADG210 and direct effect for ADGT.

The values of $c^{2}$ (Table 4) accounted for $3 \%$ to $32 \%$ of the total variability of the traits studied. The different values of correlation between direct permanent effects $\left(r_{p e}\right)$ were estimated for average daily gains (by the tested models 2, 4 and 5). Lower values of $r_{p e}$ were estimated in model 4, which included the effect of fixed regression on WW, compared with model 3.

Breeding values for ADGT, estimated routinely by the single-trait AM and the multi-trait AM (models 1 to 5), were compared on the basis of Spearman's rank correlation coefficients and are shown in Table 5 . In evaluating $10 \%$ or $5 \%$ of the best bulls, 
Table 5. Spearman's correlation coefficients among the breeding values of the best sires estimated by the single-trait animal model and all multi-bred multi-trait animal models applied

\begin{tabular}{llll}
\hline \multirow{2}{*}{ Model } & \multicolumn{3}{l}{ Top bulls } \\
\cline { 2 - 4 } & $10 \%$ & $5 \%$ & $1 \%$ \\
\hline Model 1 & 0.93 & 0.93 & 0.76 \\
Model 2 & 0.93 & 0.94 & 0.83 \\
Model 3 & 0.93 & 0.93 & 0.77 \\
Model 4 & 0.93 & 0.93 & 0.76 \\
Model 5 & 0.91 & 0.91 & 0.77 \\
\hline
\end{tabular}

Table 6 . The proportion of the best sires concurrently selected on the basis of the estimation of breding value by the single-trait animal model and all the animal models tested.

\begin{tabular}{llll}
\hline \multirow{2}{*}{ Model } & Top bulls & & \\
\cline { 2 - 4 } & $10 \%$ & $5 \%$ & $1 \%$ \\
\hline Model 1 & 91 & 90 & 93 \\
Model 2 & 91 & 90 & 94 \\
Model 3 & 91 & 90 & 93 \\
Model 4 & 91 & 90 & 93 \\
Model 5 & 90 & 89 & 91 \\
\hline
\end{tabular}

both coefficients of correlation had similar values. These coefficients showed high values of correlation (from 0.91 to 0.94 ) when all of the bulls were included. On evaluating $1 \%$ of the best bulls, lower values and larger differences were obtained for both correlation coefficients. In the group of $1 \%$ or $5 \%$ of the best bulls, the highest values of the correlation coefficients were estimated between the singletrait AM and the tested model 2. Greater differences were not found in the values of correlation coefficients between the single-trait AM and the other models (models 1, 3, 4 and 5).

Table 6 shows the proportions of the concurrently selected best sires $(10 \%, 5 \%$ and $1 \%)$ by the single-trait model and the tested models. The highest proportion of concurrently selected sires by the single-trait model was obtained if the best $1 \%$ of the animals was evaluated; the lowest proportion of concurrently selected sires was obtained with the inclusion of $5 \%$ of the best animals.

\section{Discussion}

\section{Coefficients of heritability and genetic correlation}

Negligible differences were found in the values of direct heritability coefficients $\left(h_{a}^{2}\right)$ for the daily gains. The omission of the fixed effect of HLCO resulted in a decrease in the value of $h_{a}^{2}$ in ADG120, but the value of $h_{a}^{2}$ in ADGT increased. This increase in the value of $h_{a}^{2}$ in ADGT was caused by the higher value of $\sigma^{2}$. Schenkel et al. (2004) reported markedly higher values of $h_{a}^{2}$ for average daily gains ( 0.36 for pre-weaning gains and 0.34 to 0.41 for gains during test). The values of $h_{a}^{2}$ for gains during test found by Schenkel et al. (2004) were the same as those published by Eriksson et al. (2002). Heritability estimates in this paper may differ from those published due to the higher number of different breeds included in our analysis. Another reason may be that Schenkel et al. (2004) used pre-weaning gains in the interval from birth to weaning at an average age of 212 days, whereas in the present study, this interval was divided into two sub-intervals: from birth to 120 days of age and from 120 days of age to weaning (210 days of age).

The highest values of $r_{a}$ were obtained in model 1. In the other models, the values of $r_{a}$ were influenced by the inclusion of fixed regression on WW or by the inclusion of the random effect of direct permanent environment. The high value of $r_{a}$ estimated by all tested models between ADG120 and ADG210 may be because ADG120 and ADG210 were influenced by very similar environmental conditions (grazing system). The higher value of $r_{a}$ between ADGT and ADG120, compared with ADG210, was also influenced by more similar environmental conditions than those influencing ADG210, which were affected to a greater extent by the maternal effect.

Coefficients of maternal heritability $\left(h_{m}^{2}\right)$ for average gains showed only negligible changes of the estimates obtained by different models. In contrast, a markedly lower value of $h_{m}^{2}$ was estimated for ADG210 in all of the models tested than for ADG120 and ADGT. The results show that ADG210 was influenced to a large extent by a direct effect, while maternal effect did not influence ADG210 as much. Similarly as for $h_{\sigma}^{2}$, Schenkel et al. (2004) calculated a higher value of $h_{m}^{2}$ for pre-weaning growth $\left(h_{m}^{2}=0.36\right)$ than that estimated in this paper. Schenkel et al. (2004) also confirmed our assumption that maternal effects did not substantially influence growth during the test.

The negative value of genetic correlation between direct and maternal effect $\left(r_{a m}\right)$ corresponds to biological reality. Konstantinov and Brien (2003) considered the high negative values of $r_{a m}$ as a potential expression of sire $\times$ year interaction or sire $\times$ herd interaction. These authors also stated, however, that the real value of $r_{a m}$ could be negative. Cundiff (1972) reported that moderate negative correlations between direct and maternal effects correspond to the biological constitution of these effects. Negative relationships control and balance direct and maternal effects on growth. Therefore, animal species could be prevented from adequately increasing body weight and body framework size on the one hand, 
and milk production on the other. The influences of the sire $\times$ year interaction or the sire $\times$ herd interaction on the growth abilities of beef cattle were not demonstrated in the Czech Republic (Vostrý et al., 2007). A one-sided increase in calf weight is not desirable for greater ease of calving in terms of direct or maternal effect. The positive values of $r_{a m}$ demonstrated a positive correlation between the dam's maternal traits and the animals' growth ability in a test station.

\section{Direct permanent environment}

The low value of $c^{2}$ estimated in our study was caused by a marked change in environmental conditions (i.e. rearing vs test conditions). The inclusion of fixed regression on WW had a greater influence on the estimation of $c^{2}$ in average daily gains. The inclusion of fixed regression on WW in the model decreased the value of $c^{2}$ in ADG120 and increased $c^{2}$ in ADG210. The inclusion of fixed regression on WW in the model did not have any influence on the estimation of $c^{2}$ in ADGT. The omission of the fixed effect of HLCO, similarly to the inclusion of fixed regression on WW, resulted in a decrease in $c^{2}$ in ADG210, but the omission of the HLCO effect did not influence the other traits. A comparison of these two models indicates that fixed regression on WW reduces part of the variability of the random effect of direct permanent environment. In model 5, there was a significant increase in the value of $r_{p e}$ between average pre-weaning daily gains (ADG120 and ADG210) and average daily gains in the test (ADGT). These changes can be attributed to a reduction in the variability of the direct permanent environment due to the fixed effect of HLCO.

Comparison of the values of $r_{p e}$ within the particular models showed that the highest value was estimated between ADG120 and ADGT. In contrast, the lowest value of $r_{p e}$ was calculated between ADG210 and ADGT. The negative value of $r_{p e}$ between ADG210 and ADGT may be due to the weight compensation of animals that initially had lower gains in the pre-weaning period because of herd management and environmental conditions. In contrast, the animals that had good growth in the pre-weaning period demonstrated slower growth under standardized test conditions. The negative value of $r_{p e}$ between ADG210 and ADGT becomes more important because $c^{2}$ has a low value in ADGT. Schenkel et al. (2004) concluded that such growth compensation might suggest an insufficiently long preparatory period before the start of the test. Several authors (Tong et al., 1986; de Rose et al., 1988) also estimated a mean negative environmental cor- relation ( -0.41 to -0.09$)$ between pre-weaning growth and growth in a station test. Using the testday model with random regression, Krejčová et al. (2008) also estimated negative values of $r_{p e}$ in bulls from Czech Fleckvieh cattle at performance test stations and documented growth compensation in those bulls influenced by the environment. Schenkel et al. (2004) reported that due to the influence of the aforementioned growth compensation, the problem of correct evaluation and subsequent selection of bulls for breeding may arise. These problems could be minimized by using the multi-trait model incorporating pre-weaning growth.

Higher estimates of $r_{p e}$ between ADG120 and ADGT may have been obtained because average daily gains in ADG120 are affected to a greater extent by restrictions in nutrient intake. Dams may provide their offspring with a lower amount of milk than the animal needs for full genetic growth potential.

\section{Comparison of breeding value}

The results of the prediction of breeding value demonstrated that a change in the rank of animals between the original single-trait AM and the tested model 2 was less than in the other models. Nevertheless, these results indicated potential changes in the rank of particular animals, mainly in the group of the best $1 \%$ of the animals. Similar to Spearman's rank correlation coefficient, model 2 showed the highest proportion of concurrently selected animals among the test models. Potential changes in the rank of the particular animals confirm the conclusion of the correlation analysis that there is a certain change in the rank of animals in the estimation of BV by the tested models (Table 5).

\section{Conclusions}

In general, relatively small differences were found among the evaluated models. The results document the importance of including pre-weaning information for genetic prediction of the breeding value of beef bulls at performance test stations. The moderate genetic correlation between pre-weaning growth and growth in the test stations indicates that although these traits share most of their genetic influences, they are not necessarily the same traits. The value of the direct permanent environment correlations showed that the bulls compensated in their growth during the test. Breeding value estimated by the multi-trait model, which also included pre-weaning growth, showed a certain change in the rank of animals compared with the results of the original 
single-trait AM. The multi-trait model, which also included pre-weaning growth, is more suitable for the genetic evaluation of beef bulls at performance test stations. Among the tested models (models 1 to 5), model 5 was the best. This model was selected by means of Akaike information criterion and likelihood ratio test on the basis of its lower value of $\sigma_{e}^{2}$ and its inclusion of effects that better correspond to the biological principles of growth. In contrast to the other models, this model reached higher values of $h_{a}^{2}$, lower values of $\sigma_{e}^{2}$, and better corresponded to the biological constitution of growth.

\section{Acknowledgements}

This study was supported by the 'S Grant of MSMT CR' and by the Ministry of Agriculture of the Czech Republic (Project No. MZE0002701404).

The authors wish to thank the Czech Beef Breeders Association (www.cschms.cz) for making the data available. We gratefully acknowledge the helpful comments of anonymous reviewers.

\section{References}

Bartoň L., Kudrna V., Bureš D., Zahrádková R., Teslík V., 2007. Performance and carcass quality of Czech Fleckvieh, Charolais and Charolais $\times$ Czech Fleckvieh bulls fed diets based on different types of silages. Czech J. Anim. Sci. 52, 269-276

Bozdogan H., 2000. Akaike's information criterion and recent developments in information complexity. J. Math. Psychol. 44, 62-91

Cundiff L.V.,1972. The role of maternal effects in animal breeding: VIII. Comparative aspects of maternal effects. J. Anim. Sci. 35, 1335-1337

De Rose E.P., Wilton J.W., Schaeffer L.R., 1988. Estimation of variance-components for traits measured on station-tested beef bulls. J. Anim. Sci. 66, 626-634

Eriksson S., Näsholm A., Johansson K., Philipsson J., 2002. Genetic analysis of post-weaning gain of Swedish beef cattle recorded under field conditions and at station performance testing. Livest. Prod. Sci. 76, 91-101

Henderson C.R., 1975. Best linear unbiased estimation and prediction under selection models. Biometrics 31, 423-447

Kaps M., Lamberson W., 2004. Biostatistics for Animal Science. CABI Publishing (UK), pp. 445

Konstantinov K.V., Brien F.D., 2003. Influence of sire by year interactions on the direct- maternal genetic correlation for weaning weight of Western Australian Merino sheep. Austr. J. Agr. Res. $54,723-729$
Krejčová H., Mielenz N., Přibyl J., Schuler L., 2007. Estimation of genetic parameters for daily gains of bulls with multi-trait and random regression model. Arch. Tierzucht 50, 37-46

Krejčová H., Přibyl J., Přibylová J., Štipkova M., Mielenz N., 2008. Genetic evaluation of daily gains of dual-purpose bulls using a random regression model. Czech J. Anim. Sci. 53, 227-237

Meyer K., 1998. Estimating covariance functions for longitudinal data using a random regression model. Genet. Sel. Evol. 30, 221-240

Misztal I., Tsuruta S., Strabel T., Auvray B., Druet T., Lee D.H., 2002. BLUPF90 and related programs (BGF90). In: 7th World Congress on Genetics Applied to Livestock Production. Montpellier (France)

Nephawe K.A., Maiwashe A., Theron H.E., 2006. The effect of herd of origin by year on post-weaning traits of young beef bulls at centralized testing centres in South Africa. S. Afr. J. Anim. Sci. 36, 33-39

Přibyl J., Krejčová H., Přibylová J., Misztal I., Tsuruta S., Mielenz N., 2008b. Models for evaluation of growth of performance tested bulls. Czech J. Anim. Sci. 53, 45-54

Přibyl J., Misztal I., Príbylová J., Šeba K., 2003. Multiple-breed, multiple-traits evaluation of beef cattle in the Czech Republic. Czech J. Anim. Sci. 48, 519-532

Přibyl J., Přibylová J., Krejčová H., Mielenz N., 2008a. Comparison of different traits to evaluate the growth of bulls. Czech J. Anim Sci. 53, 273-283

Prribylová J., Vostrý L., Veselá Z., Pribyl J., Bohmanová J., 2004. Breeding value for own growth of beef bulls in performancetest station. Anim. Sci. Pap. Rep. 22, 97-103

Schaeffer L.R., Schenkel F.S., Fries, L.A., 1997. Selection bias on animal model evaluation. J. Anim. Sci. 75, 2344-2352

Schenkel F.S., Miller S.P., Wilton J.W., 2004. Herd of origin effect on weight gain of station-tested beef bulls. Livest. Prod. Sci. 86, 93-103

Tong A.K.W., Newman J.A., Rahnefeld G.W., 1986. Pretest herd effects on station performance-test. Can. J. Anim. Sci. 66. 925-935

Vostrý L., Přibyl J., Veselá Z., Jakubec V., 2007. Selection of a suitable data set and model for the estimation of genetic parameters of the weaning weight in beef cattle. Arch. Tierzucht 50, 562-574

Vostrý L., Príibyl J., Schlote W., Veselá Z., Jakubec V., Majzlík I., Mach K., 2009. Estimation of animal $\times$ environment interaction in Czech beef cattle. Arch. Tierzucht 52, 15-22

Westell R. A., Quass R. L., Van Vleck L. D., 1988. Genetic groups in an animal-model. J. Dairy Sci. 71, 1310-1318

Willham R. L., 1972. The role of maternal effects in animal breeding: III. Biometrical aspects of maternal effects in animals. J. Anim. Sci. 35, 1972-1293

Woodward B.W., Pollak E.J., Quaas, R.L., 1992. Parameter estimation for carcass traits including growth information of Simmental beef cattle using restricted maximum likelihood with a multiple-trait model. J. Anim. Sci. 70, 2975-2985 